\title{
Features of the structural phase state of a weld produced by electron-beam welding in the submicrocrystalline grade 2 titanium alloy
}

\author{
Kirill Kurgan ${ }^{1,5 *}$, Vasily Klimenov ${ }^{1,2}$, Anatoly Klopotov ${ }^{1,3}$, Sergey Gnyusov ${ }^{2}$, Yuri Abzaev ${ }^{1}$, \\ Alexander Potekaev ${ }^{3}$, and Mikhail Marzol ${ }^{4}$ \\ ${ }^{1}$ Tomsk State University of Architecture and Building, 634003 Tomsk, Russia \\ ${ }^{2}$ National Research Tomsk Polytechnic University, 634050 Tomsk, Russia \\ ${ }^{3}$ National Research Tomsk State University, 634050 Tomsk, Russia \\ ${ }^{4}$ Polyus Scientific and Production Center JSC, 634041 Tomsk, Russia \\ ${ }^{5}$ Gazprom transgaz Surgut, LLC, Technical and Engineering Center, 628404 Surgut, Russia
}

\begin{abstract}
This paper presents the results of structural studies for a welded joint of the Grade 2 titanium alloy in submicrocrystalline and microcrystalline states produced by electron beam welding when joining 2$\mathrm{mm}$-thick plates. Microhardness distribution patterns of the Grade-2 titanium alloy in micro- and submicrocrystalline states are identified in the weld zone and heat-affected zone. These patterns reflect a difference in structural phase states. It is assumed that one of the key factors affecting both the structural state and microhardness distribution in the weld zone and heat-affected zone during electron-beam welding is high concentration of oxygen atoms embedded into the crystal lattice of $\alpha$-Ti-based solid solution.
\end{abstract}

\section{Introduction}

Welded joints of titanium alloys are given much attention due to the fact that these alloys are difficult to weld. In this context, laser welding is the most frequently discussed technology [1-4]. Its advantage is the possibility of welding in the atmosphere rather than in vacuum as in the case of electron-beam welding [5, 6]. As compared to electron-beam welding, laser welding is often associated with a higher degree of energy concentration, while the development of the electron-beam technique using plasma cathodes [7] allows highly focused electron beams to be generated. It is important here that the features of structural and phase transitions in welding of titanium alloys are associated with high heating and cooling rates, as well as with polymorphous transitions $\alpha \rightarrow \beta$ which are typical of titanium alloys.

The purpose of this study is to investigate the structural features, phase composition and microhardness in the weld zone produced by electron-beam welding of the Grade 2 titanium alloy in the submicrocrystalline state as compared to alloys in the ordinary state.

*Corresponding author: kirill_k2.777@mail.ru 


\section{Materials and Methods}

For the purpose of this study, the Grade 2 titanium alloy was chosen. Samples in the submicrocrystalline state were made of this alloy. The submicrocrystalline state was obtained by rolling bars with a cross section of $6 \times 6 \mathrm{~mm}$ produced by one of severe plastic deformation methods (multi-axial forging) [8]. $2 \times 12 \mathrm{~mm}$ plates with a length of $30 \mathrm{~mm}$ were used as samples for welding. The samples were pre-cleaned and clamped in a special tool in such a way to avoid contact of the weld zone with the tool, for welding in a vacuum chamber of an ELS-0,5-6 industrial-scale plant. Electron beam welding of the samples was performed by a plasma cathode electron gun [7] with an accelerating voltage (V) of $28 \mathrm{kV}$, beam current (In) of $\left(\mathrm{I}_{\mathrm{n}}\right) 35 \mathrm{~mA}$, focus coil current up to $551 \mathrm{~mA}$ and a beam travel speed of $25 \mathrm{~mm} / \mathrm{s}$.

The phase composition of the initial samples and welds was determined using a DRON4-07 X-ray diffractometer with $\mathrm{Cu}_{K \alpha}$ radiation. The quantitative phase analysis was performed by Rietveld method based on processed diffractograms of the Grade 2 alloy [9].

Samples for metallographic studies were cut from welded plates perpendicular to the weld, then ground, polished and etched with a solution $\mathrm{HF}(1$ part $)+\mathrm{HNO}_{3}(2$ parts $)+$ $\mathrm{H}_{2} \mathrm{O}(7$ parts).

The weld metal structure was examined using an Olympus GX-51 optical microscope (OM) equipped with a SIAMS700 image analyzer.

The structure of the samples was analyzed by scanning electron microscopy. A TescanVega 3 SB scanning electron microscope was used for the analysis.

The microhardness was determined on cross sections of the samples at different points of the weld using an Instron Wilson Hardness Tukon 2500-6 tester with a load of 25-50 g. Microhardness was measured along five parallel "paths" in the cross-section plane. These "paths" were perpendicular to the weld. The distance between the paths is $200 \mu \mathrm{m}$.

\section{Results and Discussion}

Microstructures of the analyzed Grade 2 alloy welds in different structural states are presented below on the basis of optical metallography (Fig. 1) and scanning electron microscopy (Fig. 2) data.

According to the standard method, the weld structure is described by identifying three zones in it: I - weld zone (WZ); II - heat-affected zone (HAZ); III - parent metal zone (PM). There are interfaces between the zones that may be clear or blurred. The presence of such boundaries is typical of welding by concentrated energy flows [4].
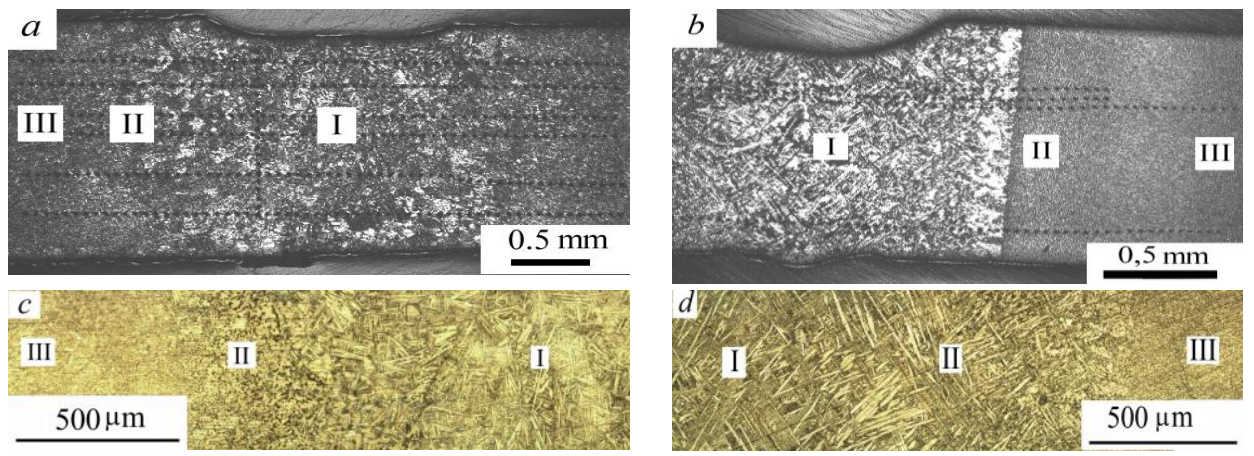

Fig. 1. The microstructure in the cross section of the Grade 2 alloy weld: $a, b$ is the general view of welds (I - weld zone; II - heat-affected zone; III - parent metal zone). 

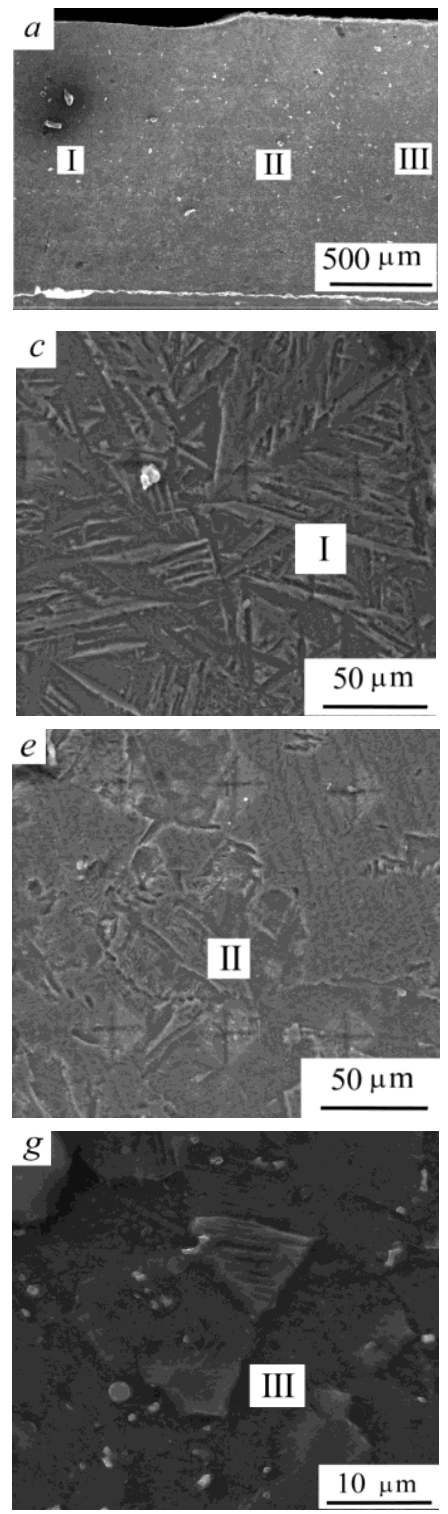
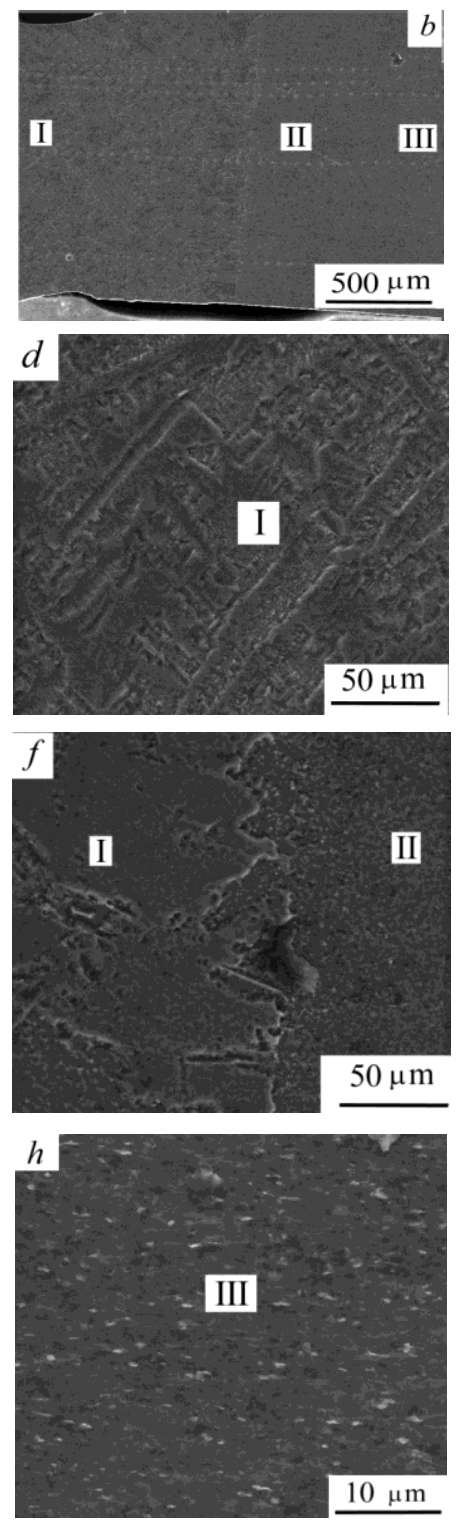

Fig. 2. Scanning electron microscopy of different zones of the Grade 2 alloy weld: general view ( $a$, $b$ ); weld zones, heat-affected and base metal zones of microcrystalline $(c, e, g)$ and submicrocrystalline $(d, f, h)$ titanium (I - weld zone, II - heat-affected zone, III - base metal zone).

When describing the weld structures for initial microcrystalline and submicrocrystalline states of the Grade 2 titanium alloy, three zones can be identified as well (Fig. 1, 2). By analyzing the structure of these microstructural images, we determined the following features. The boundary region between the HAZ and the PM zone is more blurred than that between the HAZ and the WZ. The formation of the weld is accompanied with rapid cooling both in the weld zone and in the heat-affected zone. This leads to states in weld zones that are specific in terms of structure and composition. Martensitic transformations that occur in titanium alloys are an effective strengthening mechanism that ensures 
sufficiently high strength characteristics of the weld. The presence of the $\beta$-phase is one of the features of the crystalline structure formed in the melt zone. This phase is formed as a result of quenching from a temperature above the temperature of transition to the $\beta$-phase [10].

In our case, the structural analysis of the titanium alloy weld in initial microcrystalline and submicrocrystalline states revealed a number of features (Fig. 1, 2). When a welded joint is formed under melt cooling conditions from a high-temperature $\beta$-region, the weld structure has two morphological features (Fig. 1, Fig. $2 c, d$ ): large polyhedral grains of the transformed $\beta$-phase with an average grain size of $60 \div 90 \mu \mathrm{m}$ and a plate-like intragranular structure of the $\alpha$-phase. A similar structure was observed in [1] when welding a titanium alloy in a weld after laser welding. Structural changes induced by laser welding of the Grade 2 titanium alloy led to a slight increase in the average microhardness value in the weld zone [1]. In our case, the HAZ microstructure induced by electron beam welding (Fig. 1 and Fig. $2 e, f$ ) is representative for the structure formation under conditions of gradient temperature distribution. While a mix of martensitic $\alpha$-phase and PM $\alpha$-phase grains is observed on the WZ boundary (Fig. 1), the HAZ structure on the PM boundary (Fig. 1) is mainly represented by $\alpha$-phase grains, as in the PM zone, but these grains are larger in size than that in the PM zone. In the PM zone, the titanium alloy is in the singlephase state with the $\alpha$-phase. This finding correlates with the data in [1]. According to Xray diffraction data, the $\alpha$-phase is found to have a hexagonal close-packed lattice with parameters $a=0.29761 \mathrm{~nm}$ and $c=0.47367 \mathrm{~nm}$. Using the optical metallography technique, we established that the average grain size of the $\alpha$-phase is $11.2 \pm 1.5 \mu \mathrm{m}$.

The microstructural analysis of the submicrocrystalline titanium weld joint (Fig. 1) revealed a number of features both in the PM structure and the marthensite phase structure in the weld zone. In addition, the $\beta$-phase was detected in all zones of the welded joint of the Grade 2 submicrocrystalline titanium alloy. Despite relatively rapid cooling, the WZ structure is similar to the structure formed by welding of microstructural titanium, i.e. there is a growth of grains as compared to PM grains (Fig. 1 and Fig. $2 g, h$ ). The specific feature of the PM zone in submicrocrystalline titanium is that the structure has been formed as a result of step-by-step grinding of initial titanium alloy grains by multi-axial forging with appropriate heat treatment $[11,12]$. The average grain size varies from 0.5 to $0.8 \mu \mathrm{m}$. In the weld zone, the grain size increases to $60 \div 90 \mu \mathrm{m}$. It should be noted that resistance spot welding of the Grade 2 submicrocrystalline titanium creates the quenching conditions in the WZ under which a submicrocrystalline cooling structure is formed. Growth of grains is noted in a small PM zone [13].

The structural differences of the Grade 2 titanium alloy in the microcrystalline and submicrocrystalline states are reflected in the microhardness distribution in the weld zone (Fig. 3 and 4). 

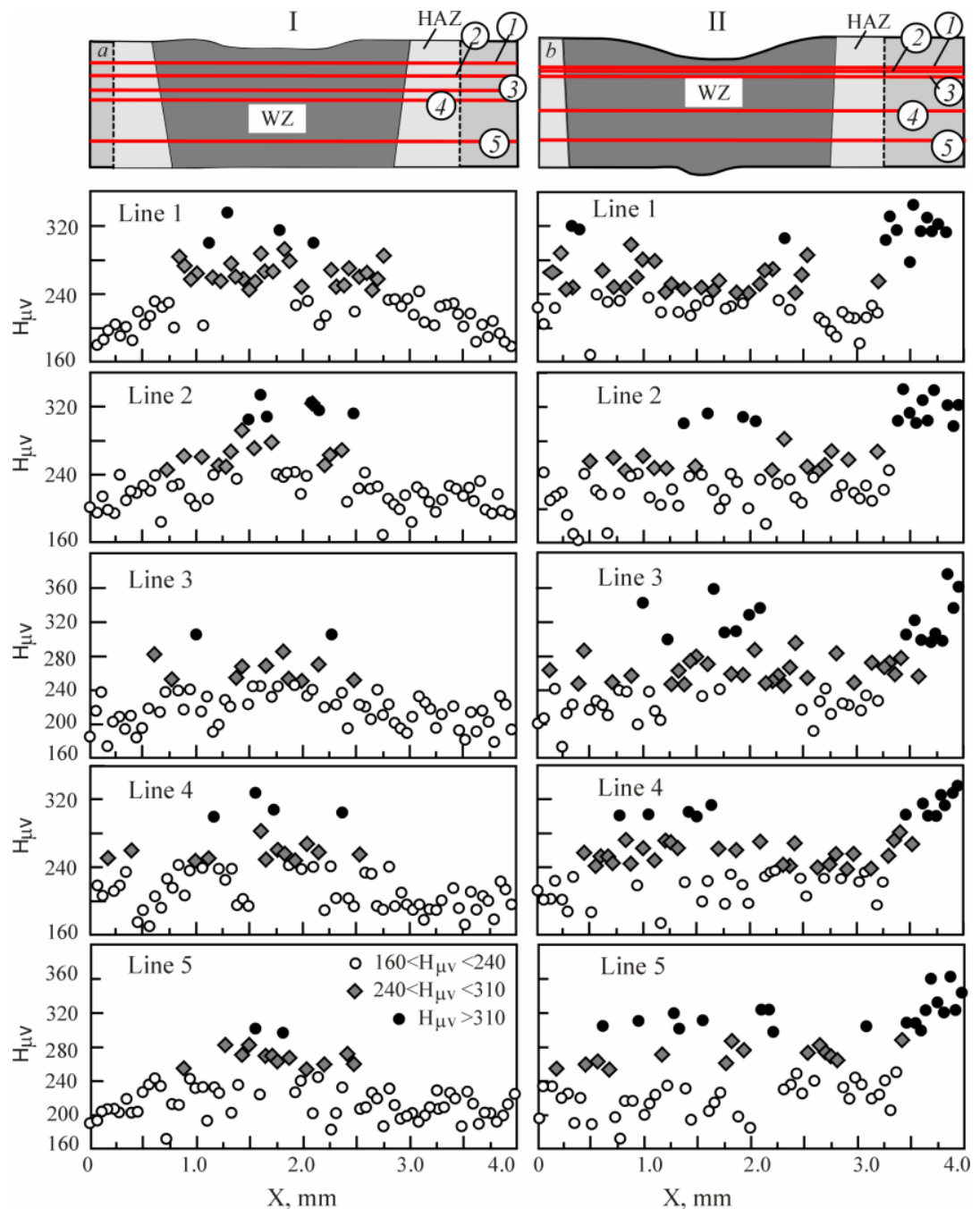

Fig. 3. Schematic representation of heat-affected zones $(a, b)$ and microhardness distribution depending on the distance along the lines $1,2,3,4$, and 5 in the weld zone in the microcrystalline (I) and submicrocrystalline (II) states of the Grade 2 alloy .

The microhardness was determined on the cross sections of the samples in the microand submicrocrystalline states of the Grade 2 alloy using different measurement procedures. In the first procedure, microhardness was measured from different weld sections along five "paths" perpendicular to the welded joint. Figure 3 shows the layout of the heat-affected zone and the microhardness distribution depending on the distance on the cross sections along the five lines. 


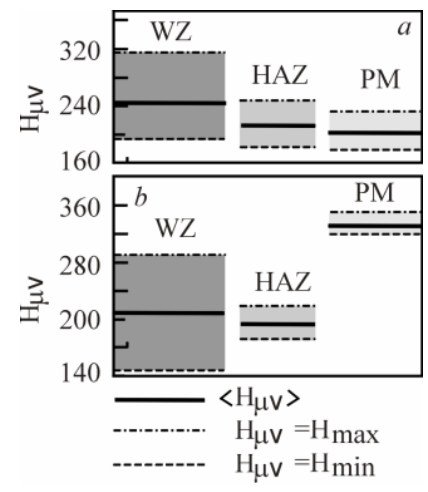

Fig. 4. Diagrams based on statistically processed microhardness data along the five lines in Figure 3 with identified zones in the weld zone in the micro- $(a)$ and submicrocrystalline $(b)$ states of the Grade 2 alloy.

A significant spread of microhardness values is observed in the weld zone and the HAZ of the tested alloy for different structural states. It can be used as an indirect indicator of structural heterogeneity of the alloy. Based on the obtained data, three typical groups can be distinguished in terms of microhardness. In Figure 3, they are highlighted by different markers. The first microhardness group includes low values with the maximum value $\mathrm{H}_{\mu \mathrm{v}}$ 230. These microhardness values are typical of the Grade 2 allow [14]. The second group includes intermediate values of $\mathrm{H}_{\mu \mathrm{V}}$ between high and low ones. The third group contains high values of $\mathrm{H}_{\mu \mathrm{V}}\left(\mathrm{H}_{\mu \mathrm{V}}>310\right)$. These values are typical of the Grade 2 alloy in the submicrocrystalline state [12]. Such a spread of microhardness values is due to the fact that an intender forced into the surface of the sample falls into different phases or into interphase boundaries every time.

By statistically processing $\mathrm{H}_{\mu \mathrm{V}}$ values obtained as a result of microhardness measurements along all paths of the test samples, we distinguished specific microhardness zones in terms of magnitude and location in the weld zone (Fig. 4). Microhardness distribution in the micro- and submicrocrystalline states of the Grade 2 alloy is characterized by close average values in the HAZ. The significant differences are observed in the microhardness distribution in the weld zone of the Grade 2 alloy in the microcrystalline state, where the average microhardness $\mathrm{H}_{\mu \mathrm{V}}$ is higher than that in the submicrocrystalline state. The spread of microhardness values $\left(\mathrm{H}_{\max }-\mathrm{H}_{\min }\right)$ in the submicrocrystalline state is much higher. This reflects a higher structural heterogeneity of the alloy in the submicrocrystalline state in the weld zone as compared to the microcrystalline state. Another situation is observed in the HAZ area and in the area far from the weld zone. Here, the spread of microhardness values $\left(\mathrm{H}_{\max }-\mathrm{H}_{\min }\right)$ in the microcrystalline state is slightly higher than that in the submicrocrystalline state (Fig. 4).

It is important to note that the structural heterogeneity of the Grade 2 alloy in these zones in the microcrystalline state is higher than that in the submicrocrystalline state. The diagrams in Figure 4 reflect the fact that a spectrum of structural phase states in the submicrocrystalline state of the Grade 2 alloy in the HAZ zone is different from the states in the microcrystalline titanium alloy. All these findings are consistent with the metallographic data presented above.

This is also reflected in the microhardness distribution in the test samples determined using another measurement procedure. According to this procedure, microhardness in the weld zone was measured on three "paths" inside and along the welded joint. Microhardness on the fourth "path" parallel to the first three ones was measured far from the weld zone in 
the base metal (Fig. 5). The above microhardness distributions depending on distances along the welded joint clearly demonstrate that the microhardness values in the weld zone are not widely scattered and differ significantly in numerical values (Fig. 5). These microhardness values far from the weld joint are typical of the Grade 2 titanium alloy in the corresponding structural states $[1, \underset{\mathrm{I}}{10}, 12,14]$.

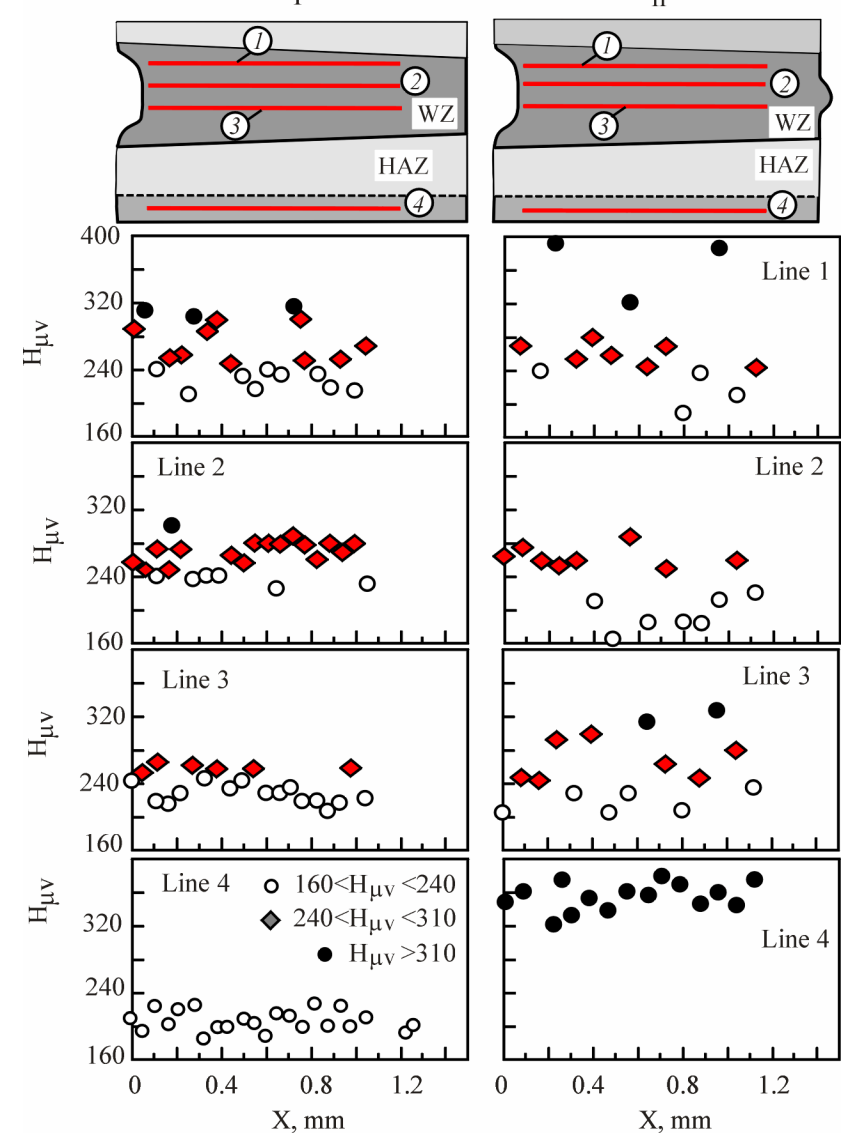

Fig. 5. The microhardness distribution depending on the distance along lines 1,2, 3 and 4 in the weld zone in the microcrystalline (I) and submicrocrystalline (II) states of the Grade 2 alloy. Different symbols denote microhardness values from different ranges.

The above microhardness distributions depending on distances in the base metal zone far from the welded joint clearly show that the microhardness of the microcrystalline alloy at the center of the weld joint (lines 2 and 3, Fig.5) has a smaller spread of values as compared to the alloy in the submicrocrystalline state, while average microhardness values in both states are close to each other. This reflects the fact that the structural heterogeneity is larger in the central part of the weld joint when the titanium alloy is in the submicrocrystalline state as compared to the microcrystalline state.

\section{Conclusion}

The welded joints produced by electron beam welding of Grade 2 titanium alloys in the microcrystalline and submicrocrystalline states were examined using structural methods 
and microhardness measurements. The findings lead to an important conclusion. In the submicrocrystalline state, the spectrum of structural phase states of the Grade 2 alloy in the weld zone and the HAZ zone is different from the states in the microcrystalline titanium alloy. The structural features of all weld zones that have been identified taking phase transitions into account determine the hardness distribution pattern and the related strength properties of compounds. This information is necessary for developing a technique aimed at optimizing physical and mechanical properties of welds produced in submicrocrystalline Grade 2 titanium alloys by electron-beam welding.

\section{References}

1. S. Gnyusov, V. Klimenov, Yu. Alkhimov, A. Budnicky, A. Orishich, A. Cherepanov, Yu. Afonin, Welding International, 1, 17 (2012)

2. H. Liu, K. Nakata, N. Yamamoto, J. Liao, Journal of Materials Science, 47, 1460 (2012)

3. T.S. Balasubramanian, V. Balasubramanian, M.A. Muthumanikkam, Journal of Materials Engineering and Performance, 20(9), 1620 (2011)

4. E. Akman, A. Damir, T. Canel, T. Sinmazçelik, J. Materials Processing technology, 209, 3705 (2009)

5. M. Weglowski, S. Błacha, A. Phillips, Vacuum, 130, 72 (2016)

6. A. Smirnova, V. Panin, Yu. Pochivalov, A. Gorbunov, A. Malikov, A. Orishich, AIP Conference Proceedings, 1785, 040071 (2016)

7. S. Wang, J. Liu, D. Chen, Materials Science and Engineering, A 584, 47 (2013)

8. J.E. Posr, D.L. Bisn, American Mineralogist, 78, 932 (1993)

9. V. Ljasockaja, Termicheskaja obrabotka svarnyh soedinenij titanovyh splavov [Thermal treatment of welded joints of titanium alloys] (Ekomet, Moscow, 2003) (in Russian)

10. G.A. Salishchev, S.Yu. Mirinov, S.V. Zherebtsov, Rev. Adv. Mater. Sci., 11, 152 (2006)

11. V. Klimenov, A. Potekaev, A. Tabachenko, M. Marzol, A. Klopotov, Reshetnevskie chteniya: proceedings of the XVIII International scientific conference (Krasnoyarsk, Siberian State Aerospace University), 1, 296 (2014)

12. K. Kurgan, V. Klimenov, A. Klopotov, Vestnik of TSUAB, 1, 140 (2016) (in Russian)

13. I. Kurzina, I. Bozhko, M. Kalashnikov, A. Eroshenko, Yu. Sharkeev, Materialovedenie [Inorganic Materials: Applied Research], 5, 48 (2010) (in Russian)

14. I. Korolev, S. Gorbunov, A. Bogdanov, G. Nadutenko, Metallovedenie titana [Metallurgy of titanium], Proceedings of the $5^{\text {th }}$ Conference on Metallurgy, Metallurgical Science and Application of Titanium and its Alloys, 117-123 (Nauka, Moscow, 1964) (in Russian) 